\title{
Dense Eosinophilic Basement Membrane Deposit
}

National Cancer Institute

\section{Source}

National Cancer Institute. Dense Eosinophilic Basement Membrane Deposit. NCI

Thesaurus. Code C158688.

Accumulation of dense eosinophilic deposits in the basement membrane. 